\title{
SERVIÇOS PÚBLICOS E MITIGAÇÃO DA POBREZA RURAL NO BRASIL ${ }^{1}$
}

\author{
José Roberto Vicente ${ }^{2}$
}

\begin{abstract}
RESUMO
0 objetivo deste estudo foi ajustar modelos de regressão hedônicos capazes de explicar valores de aluguéis de domicílios rurais em função de seus atributos, inclusive a disponibilidade de serviços públicos. Os resultados mostraram que a disponibilidade de serviços públicos aumentava nas classes de renda mais elevadas. A renda não monetária gerada pelos serviços básicos foi estimada em, aproximadamente, $\mathrm{R} \$ 90$ milhões mensais. Simulações efetuadas com esses resultados indicaram que estendendo os serviços básicos energia elétrica, água canalizada e esgoto adequado - a todos os domicílios rurais, os adicionais de renda não monetária seriam suficientes para que 245 mil a 280 mil pessoas deixassem de ser extremamente pobres, e entre 221 mil e 269 mil pessoas superassem a linha de pobreza.
\end{abstract}

Palavras-Chave: Serviços públicos. Pobreza rural. Renda não monetária. Modelos hedônicos.

\footnotetext{
${ }^{1}$ Artigo desenvolvido no âmbito de pesquisa financiada pela The United States Agency for International Development (USAID) e por um subcontrato da Broadening Access and Strengthening Input Market Systems (BASIS) / Collaborative Research Support Program (CRSP) / Universidade de WisconsinMadison com a Universidade da Califórnia em Riverside. As instituições acima não têm qualquer responsabilidade sobre as opiniões, resultados, conclusões e recomendações do trabalho. 0 autor agradece os comentários de Adriano M. R. Figueiredo, Ajax R. B. Moreira, André P. Sousa, Edward S. Levine, Eustáquio J. Reis, Gervásio C. Rezende, Juliano J. Assunção e Steven M. Helfand.

${ }^{2}$ Pesquisador científico do Instituto de Economia Agrícola (IEA-APTA), Brasil. jrvicente@iea.sp.gov.br
} 


\section{PUBLIC SERVICES AND RURAL POVERTY MITIGATION IN BRAZIL}

\section{ABSTRACT}

The objective of this study was to adjust hedonic regression models capable of explaining rental values of rural households according to their attributes, including the availability of public services. The results showed that the availability of public services increased in the higher income classes. Non-monetary income generated by basic services was estimated at approximately R $\$ 90$ million per month. Simulations performed with these results indicated that extending basic services - electricity, running water and adequate sewage - to all rural households, the additional non-monetary income would be enough to remove between 245 to 280 thousand people from extreme poverty, and bring between 221 and 269 thousand people above poverty line.

Keywords: Public services. Rural poverty. Non-monetary income. Hedonic models.

\section{INTRODUÇÃO}

A pobreza pode ser medida através de suas manifestações - as condições de $A$ habitação, alimentação, saúde, acesso a serviços básicos, mortalidade infantil, etc. 1 - ou através da renda das pessoas ou das famílias, considerando-se como pobres aquelas de renda igual ou inferior a um valor preestabelecido (HOFFMANN, 1998, p. 393).

No período de 1994 a 2002, de acordo com Kageyama e Hoffmann (2006), a pobreza medida pela insuficiência de renda, que afeta um terço da população do Brasil, apresentou variações cíclicas, sem tendência clara de melhoria. Outros tipos de pobreza, especialmente a extrema pobreza - definida pelos autores como insuficiência de renda combinada com a ausência dos três equipamentos básicos (água canalizada, banheiro e luz elétrica) - apresentaram-se sempre decrescentes no período.

Análises que utilizam a renda como indicador da qualidade de vida devem considerar, além das rendas monetárias, as não monetárias, que no caso das áreas rurais do Brasil representam a segunda fonte de renda (23,3\%), logo após os rendimentos do trabalho (IBGE, 2004, p. 89). Comparar o nível de vida de proprietários de habitações e de locatários é um dos problemas encontrados em estudos sobre pobreza e desigualdade. Ignorar essa característica pode colocar inquilinos e proprietários em níveis de rendimento similares, quando na verdade os primeiros, que suportam custo fixo mensal, podem ter nível de vida inferior. Portanto, imputações de valores de aluguéis são freqüentemente utilizadas em estudos mais bem elaborados. 
No caso de zonas rurais, existem ainda complicações adicionais para valorar serviços públicos, stricto sensu, além da dificuldade de atendimento a localidades ou domicílios isolados. Mesmo que redes de distribuição de água, por exemplo, estejam disponíveis, a possibilidade de acesso a fontes alternativas, isentas de taxas, pode levar alguns moradores a rejeitá-las, o que também pode ocorrer com o escoamento sanitário. Tipicamente, a telefonia fixa rural envolve demora na instalação ou custos elevados, no caso de serviços via satélites. Telefones celulares, por outro lado, além dos custos elevados apresentam problemas de falta de cobertura.

Apesar dessas dificuldades, avaliar os efeitos da disponibilidade de serviços públicos na zona rural sobre a renda dos beneficiários, e seus impactos sobre a redução da pobreza, pode subsidiar formuladores de políticas públicas e justificar sua implementação.

Relacionar valores de aluguéis às características dos domicílios, inclusive a existência de serviços públicos e, portanto, valorá-las, é possível partindo-se da hipótese hedônica: bens heterogêneos são agregados de atributos, e o comportamento econômico relaciona-se aos atributos, não simplesmente aos bens (TRIPLETT, 2004, p. 137). As deficiências das estatísticas nacionais, notadamente as relacionadas à zona rural, praticamente inviabilizavam esses esforços: no estudo de Reiff e Barbosa (2005), utilizando dados da Pesquisa Nacional por Amostra de Domicílios de 1999 (IBGE, 1999), apenas 6 das 22 variáveis explicativas dos aluguéis foram significativas para a zona rural, contra 17 delas para a zona urbana, resultado provavelmente devido ao pequeno número de informações rurais (346, enquanto para a zona urbana puderam ser usadas 12.390 observações).

Essa limitação foi superada pela Pesquisa de Orçamentos Familiares - POF realizada em 2002-2003, na que foram levantados, além dos valores de aluguéis de domicílios efetivamente alugados, valores de aluguéis atribuídos aos domicílios cuja condição de ocupação era diferente de alugado (IBGE, 2004, p. 25).

0 objetivo deste estudo foi ajustar e testar modelos de regressão hedônicos capazes de explicar o valor do aluguel de domicílios rurais em função de seus atributos, utilizando dados da POF 2002-2003. Com base nos resultados, procurou-se mensurar os acréscimos de renda não monetária propiciados pela disponibilidade de serviços públicos e seus impactos sobre a redução da pobreza na zona rural do Brasil.

\section{Metodologia}

Para apresentar os dados coletados na POF 2002-2003, referentes aos domicílios utilizados no ajuste dos modelos, as informações da amostra foram multiplicadas pelos respectivos pesos dos domicílios. As características domiciliares - valores de aluguéis, 
número total de cômodos, de dormitórios, de banheiros e inexistência de piso - foram discriminadas pelas grandes regiões geográficas. A disponibilidade de serviços públicos foi relacionada à classes de renda mensal per capita, tomando-se como base a agregação utilizada na POF (IBGE, 2004), composta por 4 classes: até R $\$ 600$ (3 salários mínimos de janeiro de 2003, data base da pesquisa), de $\mathrm{R} \$ 600$ a $\mathrm{R} \$ 1.200$ (de 3 a 6 salários mínimos), de $\mathrm{R} \$ 1.200$ a $\mathrm{R} \$ 3.000$ (de 6 a 15 salários mínimos), e maior do que $\mathrm{R} \$ 3.000$ (mais de 15 salários mínimos). A primeira dessas divisões, até $\mathrm{R} \$ 600$, foi subdividida em 4: até $\mathrm{R} \$ 50$, caracterizando a linha de extrema pobreza; de $\mathrm{R} \$ 50$ a $\mathrm{R} \$$ 100, linha de pobreza adotada; de $\mathrm{R} \$ 100$ a $\mathrm{R} \$ 200$, em que foram enquadradas pessoas acima da linha de pobreza, mas com renda de até um salário mínimo da época; e de R $\$$ 200 a R \$600, que compreende domicílios com renda mensal per capita de 1 a 3 salários mínimos.

A linha de pobreza adotada ( $\mathrm{R} \$ 100$ mensais per capita) corresponde à linha administrativa da pobreza à época adotada pelo Governo Federal (meio salário mínimo) para elegibilidade a vários programas sociais. Esse montante é bastante próximo do limite inferior da linha de pobreza estimada pelo Banco Mundial, com dados da POF 2002-2003, considerando o custo das necessidades básicas: $\mathrm{R} \$ 103$ mensais per capita em nível nacional, e R 94 considerando somente a zona rural (WORLD BANK, 2007, p. 21). A linha de extrema pobreza - correspondente a 1/1/4 de salário mínimo, também utilizada pelo Governo para definir o acesso a programas sociais - está relativamente próxima à linha de pobreza alimentar (food poverty line) estimada pelo Banco Mundial, valor necessário para atender as necessidades mínimas alimentares, que atingiu $\mathrm{R} \$ 61$ por pessoa por mês em nível nacional, e $\mathrm{R} \$ 58$ por pessoa por mês, considerando somente a zona rural (WORLD BANK, 2007, p. 17).

A renda domiciliar considerada foi a soma das rendas monetárias e não monetárias ${ }^{4}$, inclusive com imputação de aluguel estimado, deduzidas as despesas com manutenção, reparos, impostos, taxas de serviços e seguros com o domicílio (IBGE, 2004, p. 33). A renda mensal per capita foi obtida dividindo-se a renda domiciliar pelos habitantes do domicílio.

\section{ESPECIFICAÇÃO DO MODELO DE REGRESSÃO HEDÔNICA}

A abordagem dos preços hedônicos difundiu-se a partir do estudo de Griliches (1961), que analisou os preços de automóveis comparando um conjunto de atributos.

\footnotetext{
${ }^{3}$ Rendimentos do trabalho, transferências, rendimentos de aluguel e outros rendimentos da família (IBGE, 2004, p. 30).

${ }^{4}$ Utilização e consumo de produtos adquiridos através da produção própria, retirada do negócio, troca, doações, pagamentos em espécie, entre outros (IBGE, 2004, p. 32).
} 
Entretanto, os fundamentos teóricos para tais aplicações foram desenvolvidos por Lancaster (1966, 1971, apud NEGRI NET0, 2003, p. 82), que concebeu uma nova abordagem da teoria do consumidor baseada nas características dos bens.

A questão dos preços hedônicos foi colocada no contexto de mercado no trabalho de Rosen (1974), formulando sua teoria como um problema de equilíbrio espacial, em que um conjunto de preços implícitos guia as decisões de consumidores e produtores. Um sistema de duas equações, representando oferta e demanda, foi proposto, estimadas em um processo de dois estágios. Assumindo-se certas condições restritivas, como a igualdade de comportamento entre consumidores, o sistema de oferta e demanda colapsa em uma única equação tradicional de preços hedônicos (ROSEN, 1974, p. 44).

A especificação de equação adotada foi a exponencial, ou semilogarítmica, ou log-linear, frequentemente utilizada em estudos com modelos hedônicos; essa forma pode ser linearizada por transformação, para:

$$
\ln Y=\ln \alpha+\ln \beta x+e
$$

Onde $Y$ é a variável dependente, $x$ a(s) variável(is) explicativa(s), $\alpha$ e $\beta$ os parâmetros a estimar e $e$ o termo aleatório 5 .

Como os dados utilizados são provenientes de amostra não equiprobabilística (IBGE, 2004, p. 36), os pesos dos domicílios foram utilizados em um esquema de mínimos quadrados ponderados (JUDGE et. al., 1988, p. 359).

\section{DEFINIÇÃO DAS VARIÁVEIS UTILIZADAS (ATRIBUTOS DOS DOMICÍLIOS RURAIS)}

Os modelos de valoração dos serviços públicos nos domicílios da zona rural do Brasil foram ajustados com dados da POF de 2002-2003. A variável dependente nas equações hedônicas foi o valor atribuído ao aluguel (R\$/ano). Como variáveis explicativas foram utilizadas características dos domicílios e a disponibilidade de serviços públicos. As características selecionadas dos domicílios rurais foram o número total de cômodos, o número de dormitórios (total de cômodos servindo como dormitórios), o número de banheiros, e inexistência de piso (na verdade, existência de piso de terra ou outros); esta última, uma variável binária que assumiu valor 1 no caso de inexistência de piso de carpete, cerâmica / lajota / pedra, madeira aparelhada, cimento, ou madeira aproveitada.

\footnotetext{
${ }^{5}$ Para verificar a existência de heterocedasticidade, comum em casos de dados seccionais, foram utilizados os testes de Harvey (HILL; GRIFFITHS; JUDGE, 1999, p. 258) e de Pesaran e Pesaran (MATOS, 2000, p. 52). 
Como discutido anteriormente, as características da zona rural dificultam a oferta de certos serviços públicos stricto sensu, com exceção de energia elétrica, para a qual existem limitadas possibilidades de fontes alternativas à rede de distribuição. Localidades isoladas dificilmente poderão contar com água e esgoto ligados a redes gerais de distribuição e coleta. Parece pouco razoável exigir que 0 poder público disponibilize esses serviços, mas alternativas podem - e devem - ser colocadas ao alcance dos cidadãos da zona rural. Disponibilizar água canalizada para todos os domicílios, o que tornaria desnecessária a reutilização de água armazenada em recipientes nem sempre apropriados, potencial fonte de diversos tipos de contaminação, bem como viabilizar a construção de fossas sépticas, são medidas de políticas públicas que devem estar presentes em qualquer governo com preocupações sociais.

Presumindo-se que essas demandas são razoáveis, água canalizada e esgoto adequado (ligado à rede/pluvial ou a fossa séptica) podem ser considerados serviços públicos, ao menos lato sensu.

De acordo com essas premissas, as variáveis representativas - binárias assumindo valor 1 caso positivo, e zero caso negativo - da disponibilidade de serviços públicos experimentadas foram:
a) serviço público 1 - existência de água canalizada;
b) serviço público 2 - escoadouro do banheiro ou sanitário (esgoto);
c) serviço público 3 - existência de iluminação elétrica ligada à rede geral de distribuição;
d) serviço público 4 - existência de telefone fixo; e,
e) serviço público 5 - existência de calçamento e/ou pavimentação em toda a extensão ou no trecho do domicílio.

Naturalmente, em domicílios ou localidades isoladas a existência de pavimentação pode ser inviabilizada. 0 mesmo ocorre com a telefonia fixa convencional, via cabos, que não atinge diversas áreas, conectadas somente através de satélites. Nesse último caso, os preços elevados do serviço dificultam a ampliação do acesso. Com a evolução da telefonia celular, cujas áreas de cobertura aumentam continuamente - desde que a agência reguladora desse serviço zele para que os aumentos de escala e de produtividade resultem em preços cadentes - é provável que essa alternativa contribua decisivamente para ampliar de forma substancial a parcela da população rural beneficiada por este serviço.

Mesmo sem contar com informações referentes ao tamanho do domicílio, acredita-se não existirem problemas sérios de especificação, já que variáveis relacionadas ao número de quartos e de banheiros - junto a outras representativas de 
acesso a serviços públicos - estão entre as mais freqüentemente utilizadas nos estudos explicativos de valores de habitações revistos por Sirmans, Macpherson e Zietz (2005).

\section{RESULTADOS E DISCUSSÃO}

No ajuste dos modelos com dados da POF 2002-2003 foi possível utilizar 10.620 domicílios da zona rural sem valores perdidos (missing): 1.956 localizados na região Norte, 4.218 na região Nordeste, 1.809 na região Sudeste, 1.022 na região Sul e 1.615 na região Centro-0este.

Os valores de aluguel anual declarados variaram, em nível nacional, de $\mathrm{R} \$ 25,25$ a $\mathrm{R} \$ 49.248,00$, com média de $\mathrm{R} \$ 1.214,41$. Nas regiões, a menor das médias foi a da região Nordeste $(\mathrm{R} \$ 678,08)$, seguida pela Norte $(\mathrm{R} \$ 1.101 .91)$, Centro-Oeste ( $\mathrm{R} \$$ $1.634,50)$ e Sul (R $1.656,71)$; a região Sudeste apresentou a maior média (R\$ 1.839,20). Apenas 370 domicílios da amostra $(3,48 \%)$ estavam efetivamente alugados, por valores médios anuais entre $\mathrm{R} \$ 573,44$ (na região Nordeste) e $\mathrm{R} \$ 1.274,10$ (na região Sudeste).

A quantidade média de cômodos nos domicílios atingiu 5,52 (variando entre $1 \mathrm{e}$ 23), com dispersão relativamente pequena entre as regiões, cujas médias estiveram entre 4,34 na região Norte, e 5,87 no Sudeste. 0 número de cômodos servindo de dormitórios situou-se entre 1 e 8, com média geral de 2,01: na região Norte a média encontrada foi igual a 1,9, e no Nordeste igual a 2,07. A quantidade de banheiros nos domicílios da amostra ficou entre 0 e 13, com média inferior a 1 por domicílio em nível nacional $(0,78)$, reflexo das regiões Nordeste $(0,56)$ e Norte $(0,74)$, já que nas outras regiões foi possivel encontrar, em média, ao menos um banheiro em cada domicílio levantado. Declararam possuir piso de terra ou outros - portanto, sem piso de carpete, cerâmica / lajota / pedra, madeira aparelhada, cimento, ou madeira aproveitada - 12,25\% dos domicílios; na região Sul, apenas 0,66\% deles e, na região Norte, 22,36\%.

Com relação aos serviços públicos, energia elétrica existia em 80,9\% dos domicílios, e companhias de energia abasteciam $77,0 \%$ do total $l^{6}$. A região Sul era a mais bem servida nesse quesito (95,8\% dos domicílios com energia elétrica, e 94,1\% servidos por companhias de energia), seguida de perto pelo Sudeste $(94,2 \%$ e 93,7\%, respectivamente); já no outro extremo, a região Norte, esse serviço estava disponível em $53,9 \%$ dos domicílios, e companhias forneciam energia para 36,9\% do total. A disponibilidade de energia cresce proporcionalmente à renda: entre os domicílios com renda per capita de até $\mathrm{R} \$ 50$ mensais estava presente em 59,8\% do total; naqueles com renda ${ }^{7}$ entre $\mathrm{R} \$ 50$ e R $\$ 100$ mensais, em 67,6\%. Já dos domicílios com renda acima de

\footnotetext{
${ }^{6}$ Tabela com todos os dados não será apresentada para poupar espaço, mas pode ser solicitada ao autor.

${ }^{7}$ Desse ponto em diante, renda será empregada como renda per capita.
} 
R\$ 600 por mês, beneficiava cerca de 90\%. Essa maior concentração relativa em domicílios com maior renda repetia-se nas regiões.

Água canalizada ligada à rede geral foi declarada por 18,9\% dos domicílios; nas regiões os percentuais estavam entre $6,5 \%$ no Norte, e $27,9 \%$ no Sudeste. Já água canalizada - de rede geral, poço ou nascente e de outra forma - existia em 55,2\% dos domicílios, variando entre 23,0\% na região Norte, e 93,8\% na região Sul. A proporção de domicílios que dispunham do bem-estar proporcionado pela canalização de água, também crescia com a renda, passando de 17,0\% e 32,7\%, nos classificados, respectivamente, como extremamente pobres ou pobres, para cerca de $90 \%$ nos com renda acima de $\mathrm{R} \$ 600$ mensais. A existência de rede de abastecimento de água crescia até a classe de renda entre $\mathrm{R} \$ 600$ e $\mathrm{R} \$ 1.200$, diminuindo nas duas classes superiores, provavelmente associada a domicílios isolados de renda mais elevada.

Em apenas 5,5\% dos domicílios da zona rural o escoadouro sanitário de banheiros era ligado à rede geral ou pluvial; a melhor situação era a da região Sudeste $(17,35 \%)$, e a pior a da região Norte (0,58\%). Esgoto adequado - ligado à rede/pluvial ou fossa séptica - existia em 19,4\% dos domicílios: na região Sul esse percentual atingiu $37,0 \%$, e na região Nordeste, 7,7\%. Também nesse caso existia associação positiva entre disponibilidade e renda, nos domicílios extremamente pobres, esgoto adequado foi informado por apenas 3,7\% dos domicílios; nos pobres, o percentual foi de $10,5 \%$. Nas três classes de renda mais elevada, os percentuais situaram-se ente 31,8 e 35,8\%.

Telefones fixos estavam presentes em 7,7\% dos domicílios, e novamente o Sudeste apareceu em condição mais favorável (16,6\%), enquanto Norte e Nordeste eram os menos servidos ( $2,8 \%$ e $2,9 \%$, respectivamente). Tratando-se de serviço de custo relativamente elevado, era esperado o acentuado aumento proporcional geralmente observado na medida em que crescia a renda dos domicílios.

Calçamento e/ou pavimentação em toda a extensão ou no trecho da rua foi declarado por $10,4 \%$ dos domicílios, com extremos no Sudeste $(14,5 \%)$ e no Norte $(4,8 \%)$. Nesse caso, apesar do crescimento verificado, via de regra, com o aumento da renda, é preciso lembrar que domicílios isolados, independentemente do nível de renda, dificilmente podem contar com essa comodidade.

Os serviços básicos - energia elétrica, água de rede e esgoto adequado - existiam em $17,4 \%$ dos domicílios. Os percentuais cresciam de 1,7\% nos extremamente pobres, a $33,9 \%$ nos de renda mensal entre $\mathrm{R} \$ 1.200$ e $\mathrm{R} \$ 3.000$; na classe de renda mais elevada (superior a $\mathrm{R} \$ 3.000)$, o percentual menor $(25,6 \%)$ do que os das duas classes anteriores reflete a queda no número de domicílios com esgoto adequado, em relação a essas mesmas classes de renda. É possível que os domicílios de renda mais elevada contem com esquemas de escoadouros sanitários satisfatórios que não se pode discriminar a partir dos dados da POF. 


\section{RESULTADOS DO AJUSTE DE MODELOS HEDÔNICOS COM DADOS DA POF 2002-2003: ESTIMAÇÃO DE VALORES DE SERVIÇOS PÚBLICOS}

0 plano inicial do trabalho era ajustar um modelo em nível nacional, com variáveis binárias representativas das regiões, e em seguida modelos em nível de região, com binárias representativas das unidades da federação. Entretanto, os modelos em nível de região não forneceram bons resultados devido à diminuição de tamanho das amostras. Por isso, optou-se por ajustar um modelo em nível nacional, com variáveis binárias para 119 dos 120 setores rurais existentes na amostra ${ }^{8}$ procurando representar, da forma mais próxima permitida pela base de dados, outras características dos domicílios relacionadas à localização.

Como a variável binária relacionada aos domicílios efetivamente alugados foi significativa, decidiu-se também ajustar modelo somente com os domicílios não alugados, sobre os quais serão feitas as simulações apresentadas mais à frente. Os coeficientes estimados para as características dos domicílios e disponibilidade de serviços não diferiram nos dois modelos.

No modelo ajustado com todos os elementos da amostra, as variáveis representativas de características dos domicílios, número de cômodos, de dormitórios e de banheiros, apareceram com sinais positivos nos coeficientes estimados, enquanto que a inexistência de piso - de carpete, cerâmica / lajota / pedra, madeira aparelhada, cimento, ou madeira aproveitada - apresentou sinal negativo; a variável binária relacionada aos domicílios efetivamente alugados também teve coeficiente negativo. Todos os coeficientes associados às variáveis binárias representativas dos serviços públicos lato sensu - energia elétrica ligada à rede geral de distribuição, água encanada, esgoto adequado (de rede/pluvial ou fossa séptica), telefone fixo e pavimentação na rua do domicílio - tiveram os sinais positivos esperados, e assim como os anteriores, todos foram significativos em níveis muito baixos de probabilidade. 0 coeficiente de determinação $\left(\mathrm{R}^{2}\right)$ foi de $50,93 \%$, e os testes de Harvey e de Pesaran e Pesaran não indicaram problemas de heterocedasticidade (tabela 1). Entre as variáveis binárias representativas dos setores da amostra, 84 mostraram-se significativas a pelo menos $10 \%$ de probabilidade, 83 delas com sinais negativos ${ }^{9}$.

Dos coeficientes estimados pode-se concluir que um cômodo adicional aumentaria o valor do aluguel em 7,5\% (7,3\% no modelo sem os domicílios alugados); um dormitório adicional, em 2,8\% (2,9\%). Banheiro adicional resultaria em aluguel

\footnotetext{
${ }^{8}$ Para evitar a ocorrência de multicolinearidade perfeita (JUDGE et al., 1988, p. 430) um setor, de São Paulo (GSP27), não foi representado por variável binária.

${ }^{9}$ Ou seja, com intercepto inferior ao do setor de São Paulo (GSP27) não representado por variável binária. 
13,9\% mais elevado, e a falta de algum tipo de piso, reduziria aluguéis em 26,0\% (26,1\%). A variável representativa dos domicílios efetivamente alugados indica que iguais características resultam em aluguéis 53,6\% menores: é possível que esses domicílios estejam em piores condições, ou que os inquilinos valorem outros aspectos não considerados nos modelos, como a proximidade a empregos.

Com relação aos serviços públicos, água canalizada representava aluguel 13,9\% mais elevado (13,0\%), esgoto adequado maior em 5,8\% (6,4\%), energia elétrica em 4,1\% (4,5\%): esses serviços básicos, juntos, acrescentariam 25,6\% aos valores dos aluguéis (25,5\%, no modelo sem os domicílios efetivamente alugados). Telefone fixo ampliaria aluguéis em 43,7\% (40,8\%): nesse caso, dado o custo relativamente elevado desse serviço, notadamente em locais isolados e conectados por satélite, é provável que esse resultado em parte reflita a existência de outros serviços tipicamente urbanos, ou domicílios mais bem equipados e conservados, associados às classes de renda mais elevada. A existência de pavimentação ao menos em parte da rua onde estão localizados os domicílios encareceria os aluguéis em 10,8\% (10,6\%).

Tabela 1 - Resultados do Modelo Relacionando Valores de Aluguéis a Características dos Domicílios e à Disponibilidade de Serviços Públicos, Brasil, 2003.

\begin{tabular}{lllll}
\hline Variável & Coeficiente & Desvio-padrão & $\mathrm{t}$ & P Valor \\
\hline Intercepto & 6,73703 & 0,03710 & 181,58 & $<, 0001$ \\
Número de Cômodos & 0,07194 & 0,00418 & 17,22 & $<, 0001$ \\
Número de Dormitórios & 0,02777 & 0,00744 & 3,73 & 0,0002 \\
Número de Banheiros & 0,13027 & 0,01467 & 8,88 & $<, 0001$ \\
Domicílio sem Piso & $-0,30052$ & 0,02187 & $-13,74$ & $<, 0001$ \\
Domicílio Alugado & $-0,76828$ & 0,03639 & $-21,11$ & $<, 0001$ \\
\hline Água Canalizada & 0,13041 & 0,01811 & 7,20 & $<, 0001$ \\
Esgoto Adequado & 0,05674 & 0,01862 & 3,05 & 0,0023 \\
Energia Elétrica de Rede & 0,04060 & 0,01766 & 2,30 & 0,0215 \\
Telefone Fixo & 0,36289 & 0,02544 & 14,26 & $<, 0001$ \\
Rua Pavimentada & 0,10275 & 0,02281 & 4,50 & $<, 0001$ \\
\hline R ${ }^{2}$ & 0,5093 & $82,72\left(^{1}\right)$ & $<, 0001$ \\
\hline Teste de Harvey (heterocedasticidade) & $0,19\left(^{2}\right)$ & 0,9002 \\
\hline Teste de Pesaran e Pesaran (heterocedasticidade) & $0,00\left({ }^{1}\right)$ & 1,0000 \\
\hline
\end{tabular}

$\left.{ }^{1}\right)$ Teste F, com 128 e 10.491 graus de liberdade.

$\left.{ }^{2}\right)$ Teste F, com 3 e 10.616 graus de liberdade.

Fonte: IBGE, 2004. 
Estimados os modelos, os coeficientes obtidos foram utilizados para estimar os montantes de renda não monetária propiciados pelos serviços públicos. Apenas os domicílios não alugados foram considerados, uma vez que os inquilinos pagam aluguéis concernentes aos atributos do domicílio, inclusive os serviços públicos.

Na primeira simulação, subtraiu-se do valor do aluguel estimado pelo modelo, 0 valor também estimado pelo modelo para o mesmo domicílio desprovido de cada um dos serviços públicos existentes. Essa diferença permitiu estimar o valor de cada serviço público - stricto e lato sensu - nas diferentes classes de renda. Dividindo-se o valor total pelo número de habitantes, pôde-se estimar também a contribuição de cada serviço para a rendaper capita.

Como é comum acontecer em modelos de regressão com dados total ou parcialmente transformados por logaritmos, na equação estimada, embora as médias ponderadas dos logaritmos dos aluguéis coincidam, a média ponderada dos aluguéis estimados $(\mathrm{R} \$ 1.007,07)$ é menor do que a média dos aluguéis originais da amostra $(\mathrm{R} \$$ 1.221,28). Para contornar esse problema de subestimação, uma segunda simulação foi efetuada, calculando-se o quociente do aluguel estimado pelo modelo sem cada um dos serviços públicos, pelo aluguel estimado originalmente pelo modelo (com os serviços). 0 fator assim obtido foi multiplicado pelo valor do aluguel informado na POF 2002-2003: a diferença em relação ao valor original do aluguel forneceu 0 valor de cada serviço público, e o valor total dividido pelos habitantes, outra estimativa da contribuição desses serviços para a renda per capita.

Pelos resultados dessas simulações, a disponibilidade de energia elétrica ligada à rede gerava renda não monetária da ordem de $\mathrm{R} \$ 21,9$ milhões a $\mathrm{R} \$ 26,6$ milhões por mês, representando, em média, de $0,42 \%$ a $0,51 \%$ da renda total per capita nos domicílios atendidos por esse serviço. 0 bem-estar propiciado pela energia elétrica era relativamente maior nos domicílios abaixo da linha de pobreza, já que a renda não monetária correspondente representava entre 0,98\% e 1,07\% da renda total nos situados abaixo da linha de extrema pobreza, e de $0,71 \%$ a 0,72 para os classificados na classe seguinte, ainda abaixo da linha de pobreza.

A existência de água canalizada - aqui classificada como serviço público lato sensu - foi valorada pelo modelo em montante entre $\mathrm{R} \$ 50,9$ milhões e $\mathrm{R}$ \$ 61,9 milhões mensais, respondendo por 1,14\% a 1,39\% da renda total, em média. Entre os domicílios com rendas menores, esse serviço participava com 3,11\% a 3,90\% da renda total dos abaixo da linha de extrema pobreza, e por 2,26\% a 2,52\% daqueles acima dessa classe, mas também abaixo da linha de pobreza. Valorando-se a água canalizada ligada à rede geral pelos mesmos parâmetros, chegou-se a resultados mais modestos (entre $\mathrm{R} \$ 16,8$ milhões e R\$ 19,1 milhões/mês), devido à menor disponibilidade desse serviço público, anteriormente citada. Não obstante, o bem-estar fornecido aos habitantes dos domicílios 
que dispunham desse serviço público era bastante próximo do apresentado acima, e novamente mais significativo nas classes de renda inferiores.

Escoamento sanitário (esgoto) adequado - de rede/pluvial ou fossa séptica, considerados como serviço público lato sensu - nos domicílios representava, em média, de $0,71 \%$ a $0,81 \%$ da renda total, devido aos $\mathrm{R} \$ 11,2$ milhões a $\mathrm{R} \$ 12,8$ milhões de renda não monetária mensal que geravam. Para os domicílios com renda mensal de até $\mathrm{R} \$ 50$, o bem-estar desse serviço respondia por percentual de 1,79\% a 1,84\% da renda total, e para os domicílios com renda entre $\mathrm{R} \$ 50$ e R $\$ 100$, de 1,43\% a 1,57\%. Considerando-se apenas a renda não monetária associada ao serviço público stricto sensu, no caso esgoto de rede/pluvial, apesar da queda para menos de um terço do valor anterior, a importância relativa do serviço era ainda maior, notadamente nos domicílios de menor renda.

A renda não monetária gerada pelos serviços básicos - energia elétrica, água canalizada e esgoto adequado - atingia, pelas estimativas do modelo, entre $\mathrm{R} \$ 80,3$ milhões e R \$ 96,8 milhões por mês, o que em média representava de 1,44\% a 1,73\% da renda total dos domicílios atendidos por, pelo menos, um desses serviços. 0 bem-estar desses serviços representava quase $2 \%$ da renda total per capita dos domicílios cujos habitantes situavam-se abaixo das linhas de pobreza e de extrema pobreza.

Pavimentação ao menos em parte das ruas onde se localizavam os domicílios representou renda não monetária entre $\mathrm{R} \$ 7,8$ milhões e $\mathrm{R} \$ 9,3$ milhões mensais, o que representava, em média, 1,04\% e 1,23\%, respectivamente, da renda per capita dos habitantes desses domicílios. Como nos outros casos, a participação do bem-estar desse serviço declina com o crescimento da renda.

Tomada isoladamente, a existência de telefone fixo representou montante de renda não monetária inferior apenas ao estimado para água canalizada (entre $\mathrm{R} \$ 30,5$ milhões e R \$36,7 milhões mensais). Ressalte-se que esse serviço pode estar fortemente associado a localidades que dispunham de equipamentos tipicamente urbanos, e também a domicílios de padrão mais elevado, o que causaria maiores valores de aluguéis. Mesmo com essa consideração, os valores encontrados devem ser vistos com cuidado, especialmente no caso dos domicílios classificados como de menor renda: ainda que se desconsiderem as possibilidades de erros de preenchimento ou de sonegação de dados de renda, o pequeno número de observações positivas na amostra ${ }^{10}$ torna possível supor que a construção ou aquisição desses domicílios efetuou-se em épocas em que seus habitantes dispunham de mais renda ou, ao menos, que

\footnotetext{
${ }^{10}$ Apenas 2 domicílios na classe de renda até $\mathrm{R} \$ 50$ per capita por mês, e 23 na classe de renda entre $\mathrm{R} \$ 50$ e $\mathrm{R} \$ 100$ per capita por mês.
} 
atravessavam dificuldades conjunturais incompatíveis com o valor declarado dos aluguéis por ocasião do levantamento da POF.

0 bem-estar proporcionado pelos cinco serviços públicos, stricto sensu, considerados - energia elétrica de rede, água canalizada de rede, esgoto de rede, pavimentação e telefonia fixa - foi valorado pelos modelos entre $\mathrm{R} \$ 109,2$ milhões mensais e R $\$ 132,1$ milhões mensais. Para os domicílios que dispunham de ao menos um desses serviços, essa renda não monetária representava de 2,00\% a 2,41\% da renda total per capita, com maior participação nas classes de renda até 6 salários mínimos mensais.

Os coeficientes obtidos foram também utilizados para simular se a introdução de serviços básicos - energia elétrica, água canalizada e esgoto adequado - em domicílios sem essas comodidades, seria capaz de propiciar-lhes renda não monetária suficiente para permitir mudanças (ascensão) para classe superior. Novamente, apenas os domicílios não alugados foram considerados: dada a disponibilidade de um novo serviço básico, é razoável supor que os proprietários dos imóveis procurariam repassar a valorização correspondente para os valores dos aluguéis, de forma que não seriam apropriados como renda não monetária pelos inquilinos. Caso os proprietários dos domicílios sejam também habitantes da zona rural, a renda monetária correspondente ao aumento de aluguel resultante do novo serviço pode ser suficiente para permitir evolução de classe de renda; entretanto, essa informação não é passível de ser retirada dos dados da POF.

Como descrito anteriormente, também nesse caso foram feitas duas simulações: na primeira, subtraiu-se do novo valor do aluguel - já com o serviço público ainda inexistente - estimado pelo modelo, o valor também estimado pelo modelo para as condições originais do domicílio, portanto, sem o serviço. A diferença foi somada à renda original do domicílio, e o total foi dividido pelo número de habitantes, para propiciar a nova renda per capita do domicílio.

$\mathrm{Na}$ segunda simulação, calculou-se o quociente do aluguel estimado pelo modelo com o novo serviço, pelo aluguel estimado, também pelo modelo, sem esse serviço. 0 fator assim obtido foi multiplicado pelo valor do aluguel informado na POF 2002-203, a diferença somada à renda original do domicílio e o total dividido pelos habitantes, fornecendo outra estimativa da nova renda per capita.

De acordo com os resultados dessas duas simulações, entre 37 mil e 54 mil pessoas passariam para classes de renda superiores caso energia elétrica ligada à rede fosse disponibilizada em todos os domicílios que não dispunham de energia elétrica em 2003. 0 bem-estar adicional propiciado por tal medida de política pública impactaria quase que exclusivamente os mais pobres: de 19 mil a 24 mil pessoas sairiam da linha de extrema pobreza, e entre 9 mil e 20 mil ultrapassariam a linha da pobreza. 
Se água canalizada fosse disponibilizada para todos os domicílios que não a possuem, de 301 mil a 342 mil pessoas subiriam de classe de renda. Novamente, quase todos os beneficiados estariam nas classes de renda mais baixa: entre 126 mil e 144 mil pessoas cruzariam a linha de pobreza extrema, enquanto 134 mil a 151 mil deixariam de ser pobres.

Caso todos os domicílios com condições de escoamento sanitário provavelmente inadequadas passassem a dispor de esgoto adequado - de rede/pluvial ou fossa séptica de 274 mil a 318 mil habitantes da zona rural ascenderiam de classe de renda. Mais uma vez, as populações de baixa renda representariam a grande maioria dos beneficiados, já que entre 118 mil e 126 mil pessoas deixariam de ser enquadradas como extremamente pobres, e de 80 mil a 100 mil cruzariam a linha da pobreza.

Como resultado de uma política pública mais objetiva, que procurasse estender os serviços básicos - energia elétrica, água canalizada e esgoto adequado - a toda a população rural do País, de acordo com as simulações efetuadas entre 589 mil e 707 mil pessoas experimentariam aumentos de renda não monetária suficientes para serem enquadradas em classes de renda mais elevadas. Desse total, de 245 mil a 280 mil habitantes superariam a linha de pobreza extrema, e entre 221 mil e 269 mil ultrapassariam a linha de pobreza.

\section{CONCLUSÕES E CONSIDERAÇÕES FINAIS}

Nos modelos hedônicos explicativos dos valores de aluguéis os coeficientes estimados foram significativos e consistentes com as expectativas.

Entre as características dos domicílios da zona rural, os números de cômodos, de dormitórios e de banheiros apresentaram coeficientes positivos e significativos. A inexistência de piso (de carpete, cerâmica / lajota / pedra, madeira aparelhada, cimento, ou madeira aproveitada) influenciou negativa e significativamente os valores de aluguéis.

Com relação aos serviços públicos, a existência de telefone fixo e de pavimentação na rua do domicílio influenciaram positiva e significativamente os valores de aluguéis. Os serviços básicos - energia elétrica, água canalizada e esgoto adequado - também impactaram positiva e significativamente os aluguéis.

Os coeficientes dos modelos hedônicos permitiram valorar a existência de serviços públicos nos domicílios da zona rural em 2003: a renda não monetária gerada ficou entre $R \$ 3,5$ milhões e 61,9 milhões mensais para os serviços tomados isoladamente, com participação percentual na renda total per capita mais destacada nas classes de menor renda. Em conjunto, os serviços básicos responderam por renda não monetária entre $\mathrm{R} \$$ 80,3 milhões e $\mathrm{R} \$ 96,8$ milhões por mês, o que representava de 
1,44\% a 1,73\% da renda total per capita nos domicílios atendidos. 0 agregado de cinco serviços públicos considerados respondeu por quase $2,5 \%$ da renda total per capita nos domicílios que dispunham de ao menos um deles, atingindo montante entre $\mathrm{R} \$ 109,4 \mathrm{e}$ $\mathrm{R} \$ 132,1$ milhões mensais.

A partir dos coeficientes dos modelos hedônicos simularam-se os acréscimos de renda não monetária que resultariam da disponibilidade de serviços básicos nos domicílios não atendidos por esses serviços em 2003. Os resultados mostraram que tais políticas públicas, além de benefícios incomensuráveis - como a melhoria das condições de saúde e a conseqüente queda das taxas de mortalidade - seriam capazes de retirar da extrema pobreza entre 245 mil e 280 mil habitantes da zona rural, e de fazer superar a linha pobreza de 221 mil a 269 mil pessoas.

Em se tratando de energia elétrica, alternativas à rede geral de distribuição não estão facilmente disponíveis, e cabe ao poder público levá-la a todas as habitações. Se certas localidades ou domicílios isolados dificultam ligações às redes gerais de distribuição e coleta, é também dever do poder público viabilizar a existência de água canalizada e condições de escoamento sanitário adequado para todos os cidadãos. Como alternativa, oferecer fontes de água de qualidade próximas dos domicílios, e cuidar de oferecer os materiais necessários à canalização de água e à construção de fossas sépticas ao alcance dos orçamentos das populações rurais mais pobres, parecem ações que devem ser cobradas de governos com um mínimo de preocupações sociais.

\section{REFERÊNCIAS}

GRILICHES, Zvi. Hedonic price indexes for automobiles: an econometric analysis of quality change. In: PRICE STATISTICS REVIEW COMMITTEE (Ed.) The price statistics of the federal government: review, appraisal, and recommendations. New York: National Bureau of Economic Research, 1961. p. 173-196.

HILL, R. Carter; GRIFFITHS, William E.; JUDGE, George G. Econometria. São Paulo: Saraiva, 1999.

HOFFMANN, Rodolfo. Estatística para economistas. 3. ed. São Paulo: Pioneira, 1998.

INSTITUTO BRASILEIRO DE GEOGRAFIA E ESTATÍSTICA - IBGE. Pesquisa de orçamentos familiares 2002-2003: primeiros resultados. Rio de Janeiro, 2004.

INSTITUTO BRASILEIRO DE GEOGRAFIA E ESTATÍSTICA - IBGE. Pesquisa Nacional por Amostra de Domicílios. Rio de Janeiro, 1999.

JUDGE, George G. et al. Introduction to the theory and practice of econometrics. New York: John Wiley and Sons, 1988. 
KAGEYAMA, Ângela; HOFFMANN, Rodolfo. Pobreza no Brasil: uma perspectiva multidimensional. Economia e Sociedade, Campinas, v. 15, n. 1, p. 79-112, jan./jun. 2006.

MATOS, Orlando C. Econometria básica: teoria e aplicações. 3. ed. São Paulo: Atlas, 2000.

NEGRI NETO, Afonso. Preços hedônicos. Informações Econômicas, São Paulo, v. 33, n. 12, p. 81-83, dez. 2003.

REIFF, Luis Otávio; BARBOSA, Ana Luiza. Housing stock in Brazil: estimation based on a hedonic price model. Bank for International Settlements, Basel, n. 21, p. 257-270, apr. 2005.

ROSEN, Sherwin. Hedonic prices and implicit markets: production differentiation in pure competition. The Journal of Political Economy, Chicago, v. 82, n. 1, p. 34-55, 1974.

SIRMANS, George S.; MACPHERSON, David A.; ZIETZ, Emily N. The composition of hedonic pricing models. Journal of Real Estate Literature, Texas, v. 13, n. 1, p. 3-43, 2005.

TRIPLETT, Jack E. Handbook on hedonic indexes and quality adjustments in price indexes: special application to information technology products. Paris: OECD Publishing, 2004.

WORLD BANK. Report n. 36358-BR: Brazil measuring poverty using household consumption. Washington: World Bank, 2007. 